1 Director, UK Health Alliance on Climate Change

Cite this as: $B M J 2021 ; 375: n 2707$ http://dx.doi.org/10.1136/bmj.n2707 Published: 05 November 2021

\title{
Why tackling climate change mitigation and human health together is the best way forward
}

\author{
Amid calls to reframe the climate emergency as a health crisis, Elaine Mulcahy discusses the health \\ co-benefits of mitigating climate change
}

\section{Elaine Mulcahy'}

A recent report by the Royal Society and the Academy of Medical Sciences outlines how a focused effort that addresses the drivers and impacts of climate change could provide substantial opportunities to benefit human health.

The health of the planet and its people are closely interlinked. The impacts of climate change on health are felt both directly and indirectly, such as through heat-related deaths, respiratory problems, food insecurity, disease transmission, and inequalities.

Across many nations, we have adapted our lifestyles to a world with polluted air, highly processed foods, a high dependence on motorised travel, and a lot of time spent sitting down. This has come at a health cost.

In the UK, about $60 \%$ of the population are overweight or obese, while undernutrition affects $5 \%$ of the population. Long term exposure to air pollution causes about 30000 premature deaths in the UK every year. And in all of these cases, it is those most vulnerable who are most heavily impacted.

In the last number of months, there have been numerous interventions by the world's healthcare community voicing their concerns and calling for action to address climate change and protect health. This has included an editorial simultaneously published across 220+international health journals, and the delivery of a letter holding the signatures of organisations and individuals representing about 45 million health workers to world leaders attending COP26. ${ }^{23}$

For too long, the health burden of climate change has not featured in the climate narrative. The latest report from the Royal Society and Academy of Medical Sciences, "A healthy future - tackling climate change mitigation and human health together" says that it is time for this to change. It calls for a stronger focus on health within the international climate narrative, and for the UK Government to advocate for this: "By integrating the protection and promotion of human health in all actions to address climate change in the $U K$ and demonstrating the potential health gains of the net-zero transition, the UK can take a global leadership role."

Phasing out fossil fuels and reducing greenhouse gas emissions through renewable energy, more energy-efficient housing, healthier dietary choices, and more active travel will all help to address climate change and improve health.
For example, the report illustrates that replacing half of UK meat and dairy consumption with fruit, vegetables and cereals, would result in a 19\% reduction in agricultural greenhouse gas emissions, while also avoiding or delaying 37 ooo deaths a year from coronary heart disease, stroke and diet-related cancer. Increased uptake of public transport and active travel with a transition away from private motor vehicle use, could lead to improvements in health combined with significant savings on healthcare costs as a result of reduced air pollution and higher levels of physical activity. And, an $80 \%$ reduction in greenhouse gas emissions in power generation systems by 2050 , would result in a $60 \%$ reduction in $\mathrm{NO} 2$ levels in the air and save 7 million life years because of reduced exposure to $\mathrm{NO}_{2}$.

While government policy and action is critical to the success of action on climate change, the decisions we make as individuals are also essential to reducing emissions.

The report states that more than half of the emission reductions required to meet net zero will require changes to individuals' behaviour, such as by choosing low-carbon technologies, diets or travel options. Highlighting the advantages of climate mitigation and adaptation measures for health will be key to increasing public support for action.

For example, encouraging active travel through increased walking and cycling will contribute to emissions reductions while also improving physical fitness and reduced risk of diabetes, cardiovascular disease, cancer, and musculoskeletal disease. Improved access to green space can improve mental health and wellbeing and social connections. Communications that articulate the health rewards of climate mitigation actions will play a vital part in the societal and cultural shift that will be needed to move away from our current reliance on cars, processed foods, and heating.

Regularly measuring, demonstrating and communicating the health impacts of climate action will be important to ensure we properly harness the benefits. The report calls for national and local governments to work with researchers and public health to prioritise the integration and refinement of metrics to ensure robust systems are in place that capture the broad scope of health, society and equity. Multiple sectors will also need to work together to further explore and understand the interaction of climate mitigation on health, including inequities and factors that affect behaviour change, so that areas 


\section{OPINION}

for targeted intervention can be identified and understood.

This report is further evidence of the connection between climate change and human health that spans mental health and wellbeing, physical health, nutrition, and inequalities. As we put in place policies and actions that challenge our current way of life, we have an opportunity to both protect the planet and improve our health.

Competing interests: none declared

Provenance and peer review: Not commissioned, not peer reviewed

1 The Academy of Medical Sciences. A healthy future-tackling climate change mitigation and human health together. October 2021. https://acmedsci.ac.uk/file-download/11365167

2 Atwoli L, Baqui AH, Benfield T, etal. Call for emergency action to limit global temperature increases, restore biodiversity, and protect health. BMJ2021;374:n1734.

doi: 10.1136/bmi.n1734 pmid: 34483099

3 https://healthyclimateletter.net/ 